\title{
ЖЕЛЧНОКАМЕННАЯ БОЛЕЗНЬ. МУЛЬТИДИСЦИПЛИНАРНЬЙ ПОДХОД К РЕШЕНИЮ ПРОБЛЕМЫ (ОБЗОР)
}

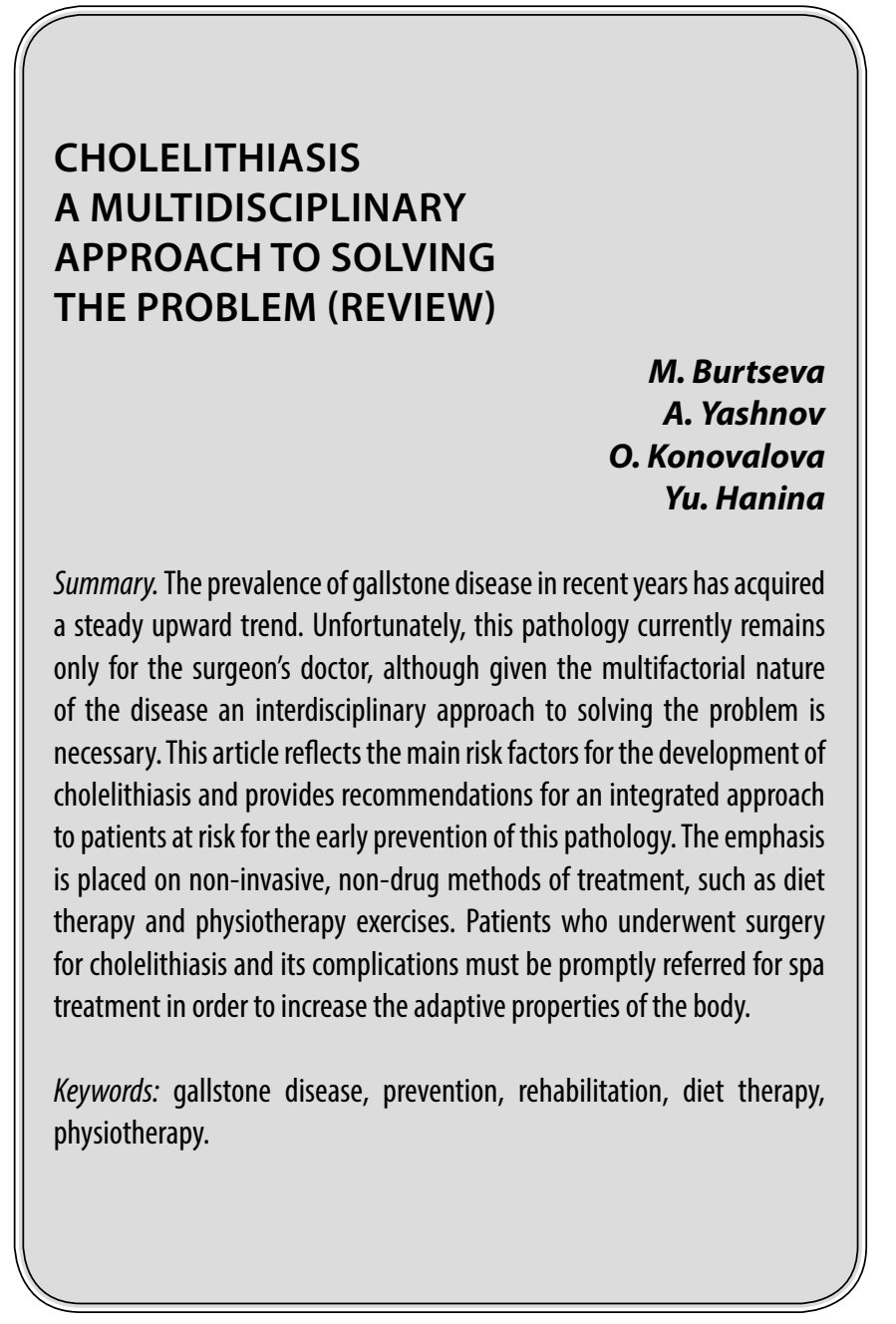

X елчнокаменная болезнь (ЖКБ) является актуальной проблемой современной медицины. В среднем до 10\% жителей планеты страдают от данной патологии [1,2,3,4]. С точки зрения абдоминальной хирургии - холецистэктомия является одной из самых частых оперативных вмешательств. Учитывая распространенность жизнеугрожающих осложнений холелитиаза, проблему желчнокаменной болезни стоит рассматривать с точки зрения мультидисциплинарного подхода. С одной стороны - заинтересованный, грамотный врач терапевт, который должен заниматься непосредственно профилактикой желчнокаменной болезни, с другой стороны врач хирург - основная задача которого в максимально безопасном, адекватном консервативном и хирургическом лечении различных форм калькулезного холецистита и его осложнений. Вместе с тем,

\author{
Бурцева Мария Александровна \\ ФГБОУ ВО Читинская государственная медицинская \\ академия \\ burseva94@mail.ru \\ Яшнов Алексей Александрович \\ К.м.н., ассистент, ФГБОУ ВО Читинская \\ государственная медицинская академия \\ Коновалова Ольга Геннадьевна \\ К.м.н., дочент, ФГБОУ ВО Читинская \\ государственная медицинская академия \\ Ханина Юлия Сергеевна \\ К.м.н., дочент, ФГБОУ ВО Читинская \\ государственная медицинская академия
}

Аннотация. Пораженность населения желчнокаменной болезнью в последние годы приобрела устойчивую тенденцию к росту. К сожалению, данная патология в настоящее время остается уделом только врача хирурга, хотя учитывая мультифакториальность заболевания необходим междисциплинарный подход к решению проблемы. В данной статье отражены основные факторы риска развития желчнокаменной болезни и приведены рекомендации по комплексному подходу к пациентам из групп риска сцелью ранней профилактики данной патологии. Акцент сделан именно на неинвазивные, не медикаментозные способы лечения, такие как диетотерапия и лечебная физкультура. Пациентов, перенесших оперативное вмешательство по поводу желчнокаменной болезни и ее осложнений, необходимо своевременно направлять на санаторно-курортное лечение, с целью повышения адаптационных свойств организма.

Ключевые слова: желчнокаменная болезнь, профилактика, реабилитация, диетотерапия, лечебная физкультура.

у пациентов с высоким риском развития холелитиаза с целью превентивного подхода к проблеме необходимо основной акцент делать на неинвазивные и немедикаментозные (лечебную физкультуру и диетотерапию) способы лечения, а также профилактики развития желчнокаменной болезни и ее осложнений $[5,6,7,8]$. С целью снижения нежелательных последствий оперативного лечения (ПХЭС, спаечная болезнь) пациентам необходима своевременная реабилитация[9,7].

Современные тенденции российского здравоохранения направлены на профилактику, лечение и реабилитацию, в основном, пациентов сердечно-сосудистого профиля. Вместе с тем, не стоит забывать, что по летальности от осложнений желчнокаменная болезнь не уступает инфарктам и инсультам [1,2,3,4]. 
В данной статье основной акцент сделан на профилактику развития желчнокаменной болезни и ее осложнений. Для начала стоит разобраться в основных звеньях этиологии и патогенеза, чтобы понять на какие точки приложения необходимо воздействовать в группе пациентов с высоким риском и уже подтвержденным диагнозом.

Причины образования камней в желчном пузыре и желчевыводящих путях множественны, но до конца не изучены. Многие авторы отмечают, что основную роль в развитии холелитиаза играют 3 процесса:

- снижение эвакуаторной функции желчного пузыря;

- травматизация и воспаление слизистой оболочки желчного пузыря;

- изменение биохимических и реологических свойств желчи[1,2,3].

Камнеобразование связывают с определенным пищевым поведением: редкие, но обильные приемы пищи с избытком белков животного происхождения, твердых жиров, большим количеством легкоусвояемых углеводов и низким содержанием растительной клетчатки $[1,2,3,4]$. Все это приводит к неравномерному желчевыделению, перерастяжению желчного пузыря, сменяющегося резким его сокращением, как следствие - травматизацией и воспалению слизистой. Несбалансированное питание приводит к дисбалансу между факторами, способствующими и препятствующими выпадению холестерина в осадок, что создаёт условия для кристаллизации холестерина $[3,6,7,10]$. Отсюда определено, почему одним из основных факторов риска является ожирение. Доказано, что у пациентов с ИМТ больше 25 кг/м2 риск развития ЖКБ увеличивается в 2 раза, при ИМТ свыше 35 кг/м2 в 20 раз. Так же установлено, связь наличия у пациента дислипидемии, с увеличением общего холестерина и атерогенных ЛПНП И ЛПОНП, и конкрементов желчного пузыря [10].

Некоторые авторы особую роль отводят генетическим факторам, описано до 50 генов, так или иначе участвующих в патогенезе желчнокаменной болезни $[1,2,3]$.

Особое место в структуре факторов риска занимает эндокринная теория $[2,11,13,14]$. Согласно статистике у женщин конкременты желчного пузыря обнаруживают в разы чаще, чем у мужчин (соотношение 4:1). Многие авторы утверждают, что гормональные стимулы оказывают гораздо большее влияние на моторику желчного пузыря и желчевыводящих путей сильнее, чем нервные[2,11,13,14]. Кроме того, через гормоны реализуется и механизм регуляции обмена жиров, наибольшей липотропной активностью обладают гормоны гипофиза, за счет влияния на органы мишени, вырабатываю- щие - тироксин, трийодтиронин, инсулин, эстроген, прогестерон и т.д. Низкий уровень тестостерона в крови у женщин влияет на риск развития ожирения и метаболического синдрома, что вместе с липотропным действием эстрогенов, что и делает женщин более подверженными камнеобразованию $[2,11,13,14]$.

О взаимосвязи желудка и желчевыводящих путей известно еще со времен С.П. Боткина, который в своих трудах отмечал, что возможно сочетание поражений желудка и желчного пузыря у одного и того же пациента $[3,12,14]$. В пользу этого говорят и промежуточные результаты нашего исследования в рамках комплексной диагностики пациентов с различными вариантами острого калькулезного холецистита. Всем пациентам, учувствовавшим в исследовании, была выполнена эзофиброгастродуоденоскопия. Всего обследовано 65 пациентов, находящихся на лечении в отделении хирургии с подтвержденным холелитиазом. Из 65 пациентов только 1,5\% оказались без патологии со стороны желудка. Изменения со стороны слизистой желудка в виде смешанного гастрита обнаружены у 33 пациентов, что от общего числа составляет 50,7\%, диагноз атрофический гастрит выставлен 15 пациентам, что составляет 23,07\%. Поверхностный гастрит встречается у 4,61\% пациентов, рефлюкс-гастрит у 3,07\%. Вместе с тем, у пациентов, которым не выставлен диагноз гастрит, обнаружены различные формы гастропатии, из них эритематозная форма гастропатии встречается у 10,76\% пациентов, катаральная гастропатия встречается у 3,07\% больных с желчнокаменной болезнью.

Таким образом, учитывая все факторы риска можно выделить несколько групп пациентов, которым необходимы ранние превентивные мероприятия, с целью предупреждения холелитиаза:

- пациенты с дислипидемией, подтвержденной лабораторно с или без поражений органов мишеней (ИБС, инфаркты, инсульты, генерализованный атеросклероз сосудов);

- пациенты с гастритами и гастропатиями, выявленными случайно или находящиеся на учете по данной патологии;

- это пациенты с ожирением и метаболическим синдромом, беременные и многократно рожавшие женщины с отягощенной наследственностью по желчнокаменной болезни;

- пациенты с дискинезией желчевыводящих путей по гипо-/гипермоторному типу.

Зачастую первоначально пациенты обращаются именно в поликлинику, к врачу терапевту и ему важно вовремя сориентироваться, объяснить необходимость соблюдении минимального набора профилактических мероприятий. Вместе с тем, на уровне первичного звена 

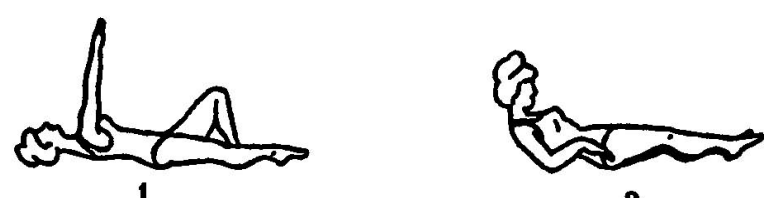

2
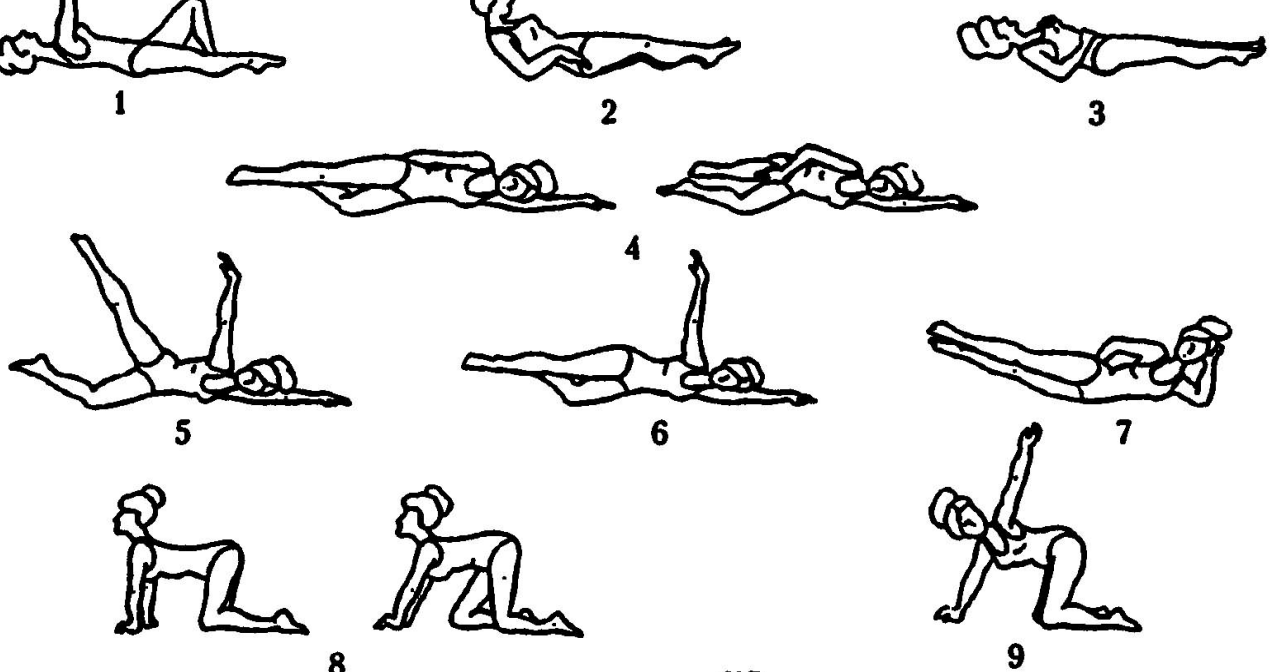

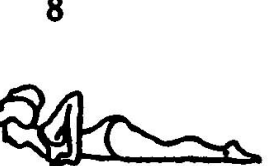

10

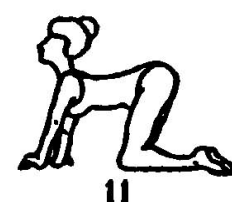

11

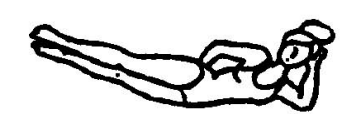

7

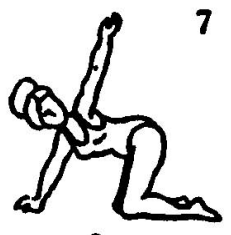

9

Рис. 1. Комплекс упражнений для профилактики и лечения желчнокаменной болезни.

следует направлять таких пациентов на консультацию к врачу лечебной физкультуры, врачу диетологу, врачу реабилитологу (касаемо пациентов, перенесших оперативное вмешательство).

Доказано, что ряд упражнений положительно влияет на моторику желчевыводящих путей, снимает спазм со сфинктера Одди, улучшает моторику желудочно-кишечного тракта, ускоряя пассаж пищи и тем самым предупреждая чрезмерное всасывание желчных кислот (Рис. 1) $[2,5,8]$. Учитывая простоту упражнений, их можно рекомендовать пациентам с различным уровнем физической подготовки, подбор упражнений должен осуществляться врачом ЛФК с учетом персонализированного подхода к пациенту (Таб. 1).

Наблюдение у врача диетолога так же необходимо пациентам из групп риска, так как коррекция рациона может существенно снизить риск развития желчнокаменной болезни $[3,6,10]$. Еще М.И. Певзнер писал о том, что лучшим средством для профилактики застоя желчи является частый прием пищи. Дробное питание, помимо прочего помогает избежать переедания, избежать дефицита необходимых макро- и микронутриентов. Основные догмы диетологии применимы и к пациентам с высоким риском, и к пациентам с уже подтвержденным камненосительством [3,6,10]. Достаточное количество белка, в среднем 1г на кг идеальной массы тела, при чем качество поступающих белков должно быть разно- образным - 50\% должно приходиться на белки животного происхождения (мясо, рыба, яйцо, птица, молочные продукты), оставшиеся 50\% допустимо получать из продуктов растительного происхождения - бобовые, соя. Количество потребляемых жиров таким пациентам должно подбираться индивидуально, вопреки мнению, что большое количество жиров вредно для организма, диетологи придерживаются мнения, что для полноценного питания необходимо потребление разнообразных жиров. Установлено, что они богаты необходимыми организму арахидоновой, линоленовой, линолевой кислот, которые улучшают усвоение жирорастворимых витаминов А, К. Е, Д [6,10]. Безусловно, потребление тугоплавких жиров (говяжий, бараний, свиной) необходимо ограничивать, так как они плохо усваиваются, в них высокое содержание холестерина и насыщенных жирных кислот, тем самым они провоцируют образование холестериновых камней. Среднесуточная норма потребления жиров 70-80 г, из которых 25-30 г растительного происхождения. Ограничение потребления жиров до 50 г в сутки рекомендовано пациентам в ранний восстановительный период после холецистэктомии и пациентам со стеатореей любого генеза. С целью усилить желчегонное действие пищи количество жиров увеличивают до 100-120г/сут, за счет растительных жиров. Такую диету назначают пациентам на короткий срок, до 3 недель. Уменьшение потребления поваренной соли до 3 г/сут и простых легкоусвояемых углеводов до 10\% от суточной нормы рекомендовано пациентам из групп 
Таблица 1. Перечень упражнений для лечения и профилактики желчнокаменной болезни.

\begin{tabular}{|c|c|c|}
\hline \multicolumn{3}{|c|}{ Комплекс упражненнй для оттока желчи } \\
\hline № & Описание & Рисунок \\
\hline 1 & $\begin{array}{l}\text { Диафрагмальное дыхание. Делаем вдох через н } \\
\text { через рот, параллельно втягивая живот (6 раз). }\end{array}$ & нно выдыхаем \\
\hline 2 & $\begin{array}{l}\text { Лечь на спину, руки вдоль тела, ноги вместе. На } \\
\text { вдохе поднимаем правую руку вверх и сгибаем } \\
\text { в колене левую ногу, не отрывая ступню от } \\
\text { пола. На выдохе возвращаемся в начальное } \\
\text { положение (4 раза для каждой пары руки и } \\
\text { ноги). }\end{array}$ & \\
\hline 3 & $\begin{array}{l}\text { Лечь на спину, руки на поясе, ноги вместе. На } \\
\text { выдохе приподнимаем плечи и голову, так } \\
\text { чтобы увидеть носки ног. Возвращаемся в } \\
\text { исходное положение. Вдыхаем. Повторяем } 4 \\
\text { раза. }\end{array}$ & \\
\hline 4 & $\begin{array}{l}\text { Лечь на спину, согнуть ноги, руки вдоль тела. } \\
\text { Вдохнуть, на выдохе подтянуть колени и } \\
\text { подбородок к груди. Ноги обхватить руками. } \\
\text { Вернуться в исходное положение. Сделать } 4 \\
\text { раза. }\end{array}$ & \\
\hline 5 & $\begin{array}{l}\text { Лечь на спину, руки вдоль тела, ноги вместе. } \\
\text { Согнуть правую ногу, выпрямить её, затем } \\
\text { проделать тоже самое другой ногой. } \\
\text { Упражнение должно имитировать ходьбу. } \\
\text { Выполнять } 1 \text { мин. }\end{array}$ & \\
\hline 6 & $\begin{array}{l}\text { Лечь на спину, ноги согнуты, стопы и колени } \\
\text { вместе. Поочередно наклоняем сомкнутые } \\
\text { колени в разные стороны (по } 4 \text { раза). } \\
\text { Упражнение выполняется после вдоха на } \\
\text { выдохе. }\end{array}$ & \\
\hline 7 & $\begin{array}{l}\text { Лечь на спину, руки вдоль тела, ноги вместе. } \\
\text { Согнуть правую ногу, выпрямить её, вернуться в } \\
\text { исходное положение. Проделать то же самое } \\
\text { другой ногой (по } 4 \text { раза). }\end{array}$ & \\
\hline 8 & $\begin{array}{l}\text { Лечь на спину, локтями упереться в пол, ноги } \\
\text { согнуты, стопы немного расставлены. После } \\
\text { вдоха на выдохе приподнять таз. Вернуться в } \\
\text { исходное положение ( } 4 \text { раза). }\end{array}$ & \\
\hline 9 & $\begin{array}{l}\text { Лечь на левый бок, левая нога полусогнута, } \\
\text { левая рука лежит на полу, продолжая линию } \\
\text { тела. На вдохе поднимаем правую руку через } \\
\text { сторону до параллели слевой рукой. На выдохе } \\
\text { приводим правое колено к груди, прижимая } \\
\text { его к телу правой рукой. Возвращаемся в } \\
\text { исходное положение. Повторяем } 4 \text { раза. }\end{array}$ & \\
\hline
\end{tabular}


риска и с подтвержденным диагнозом следует с целью уменьшения воспаления слизистой желчного пузыря. С целью профилактики запоров и для гидрохолереза необходимо достаточное потребление воды - в среднем до 2л/сут, грубых пищевых волокон - пектина, целлюлозы и гемицеллюлозы, получаемых из овощей, фруктов, ягод. Основные положения, касаемо питания отражены в приказы МЗ РФ 33 0о 05.08.2003г диета с механическим и химическим щажением, в основе который лежат компоненты диет № 5 и 5 а по Певзнеру $[6,10]$.

Санаторно-курортное лечение наиболее эффективно для пациентов, перенесших холецистэктомию, с целью воздействовать на основные звенья патогенеза нарушений, развивающихся после холецистэктомии. [7,9] К сожалению, влияние природных физических факторов на клинико-метаболический статус у больных с удаленным желчным пузырем, изучено недостаточно. Однако можно предполагать о благоприятном воздействии маломинерализированной слабоуглекислой сульфатно-гидрокарбонатной кальциево-натриевой минеральных вод для внутреннего и наружного применения с целью повышения адаптационного порога организма. [7,9] В совокупности с соблюдением диеты и достаточным уровнем физической активности возможно снижение риска возникновения постхолецистэктомического синдрома, спаечной болезни в отдаленном периоде.

Резюмируя приведённые сведения, можно сделать вывод, что проблема желчнокаменной болезни, несмотря на длительную историю изучения холелитиаза, остается актуальной проблемой на стыке хирургического и терапевтического профиля. Основная задача современной медицины - избежание грозных осложнений калькулезного холецистита. Как следствие, необходим комплексный подход, прежде всего, к профилактике данного заболевания. Важно на этапе первичного звена оценивать риски развития желчнокаменной болезни, направлять пациентов из групп риска на комплексное обследование. Такие больные должны находиться под наблюдением не только у врача терапевта, но и у врача гастроэнтеролога, врача диетолога, врача лечебной физкультуры и врача реабилитолога.

\section{ЛИТЕРАТУРА}

1. Вахрушев Я. М. Желчнокамення болезнь (эпидемиология, ранняя диагностика, диспансеризация).— Ижевск, 2014. $124 c$.

2. Григорьева И. Н. Основные факторы риска желчнокаменной болезни // Российский журнал гастроэнтерологии, гепатологии и колопроктологии - 2007 - № 6- С. 17-21

3. Ивашкин В. Т. Болезни печени и желчевыводящих путей. Руководство для врачей. - Москва — М-Вести, $2002-$ C. 416

4. Призенцов А. А. Желчнокаменная болезнь: состояние проблемы //Проблемы здоровья и экологии,_2012 — № 3 - С. 39-44

5. Ким С.Л. Лечебная физкультура при желчекаменной болезни // Научные исследования и разработки студентов: материалы V Междунар. студенч. науч. — практ. конф. (Чебоксары, 30 окт. 2017 г.) / редкол.: 0. Н. Широков [и др.] — Чебоксары: ЦНС «Интерактив плюс», 2017.— С. 37-39

6. Назаренко Л. И. Возможности диетотерапии и типичные ошибки в питании пациентов с заболеваниями желчевыводящих путей // Экспериментальная и клиническая гастроэнтерология — 2013 - № $2-$ С. 83-88

7. Хайлачева И.С. Санаторно-курортное лечение больных с постхолецистэктомическим синдромом с применением методов, воздействующих на адаптационные процессы: автореф. дис. ... канд. мед. наук: 14.00.51 — Пятигорск, 2009. - 138 с.

8. Шарафанов А. А. Лечебная физкультура при заболеваниях органов пищеварения, мочеполовой системы и обмена веществ, - Ставрополь: Кн. изд-во, 1982 г.

9. Адилов В. Б. История санаторно-курортного дела в России. Природные лечебные факторы России. // Актуальные проблемы восстановительной медицины, курортологии и физиотерапии. Мат. Междунар. конгресса «Здравница-2008». 2008. - С. 14-22

10. Григорьева И. Н. Роль гиперлипидемии при желчнокаменной болезни // Экспериментальная и клиническая гастроэнтерология - 2010 - № 4 - С. $64-$ 68

11. Асланов, А. М. Гендерные особенности секреции стероидных гормонов у больных с желчнокаменной болезнью // Медицинские науки. - 2015.— № XI (18). - C. 46-49

12. Бондаренко В. А. Хирургическое лечение больных при сочетании язвенной болезни и желчнокаменной болезни // Кубанский научный медицинский вестник - 2012 - № $2-$ C. 40-42

13. Вахрушев Я. М. Желчнокаменная болезнь: эпидемиология, факторы риска, особенности клинического течения, профилактика // Архив внутренней медицины. - 2016. № 3(29) - С. 30-32

14. Вахрушев, Я. М. Роль гормонов в развитии желчнокаменной болезни // Экспериментальная и клиническая гастроэнтерология. — 2008. — № 2. — С. 5762

\footnotetext{
( Бурцева Мария Александровна ( burseva94@mail.ru ), Яшнов Алексей Александрович,

Коновалова Ольга Геннадьевна, Ханина Юлия Сергеевна.

Журнал «Современная наука: актуальные проблемы теории и практики»
} 